\title{
Chlorophyll $a$ fluorescence as a tool to monitor physiological status of plants under abiotic stress conditions
}

\author{
Hazem M. Kalaji ${ }^{1}$ - Anjana Jajoo $^{2}$ - Abdallah Oukarroum ${ }^{3} \cdot$ Marian Brestic $^{4}$ • \\ Marek Zivcak $^{4} \cdot$ Izabela A. Samborska $^{1} \cdot$ Magdalena D. Cetner $^{1} \cdot$ Izabela Lukasik $^{5}$. \\ Vasilij Goltsev $^{6} \cdot$ Richard J. Ladle $^{7,8}$
}

Received: 11 April 2015/Revised: 29 February 2016/Accepted: 1 March 2016/Published online: 29 March 2016

(C) The Author(s) 2016. This article is published with open access at Springerlink.com

\begin{abstract}
Plants living under natural conditions are exposed to many adverse factors that interfere with the photosynthetic process, leading to declines in growth, development, and yield. The recent development of Chlorophyll $a$ fluorescence $(\mathrm{ChlF})$ represents a potentially valuable new approach to study the photochemical efficiency of leaves. Specifically, the analysis of fluorescence signals provides detailed information on the status and function of Photosystem II (PSII) reaction centers, lightharvesting antenna complexes, and both the donor and acceptor sides of PSII. Here, we review the results of fast ChlF analyses of photosynthetic responses to
\end{abstract}

Communicated by AK Kononowicz.

Hazem M. Kalaji

hazem@kalaji.pl

Anjana Jajoo

anjanajajoo@hotmail.com

Abdallah Oukarroum

oukarroum.abdallah@uqam.ca

Marian Brestic

marian.brestic@uniag.sk

Marek Zivcak

marek.zivcak@uniag.sk

Izabela A. Samborska

izabelasam@wp.pl

Magdalena D. Cetner

magdalena.cetner@gmail.com

Izabela Łukasik

zzlukasik@gmail.com

Vasilij Goltsev

goltsev@biofac.uni-sofia.bg; goltsev@gmail.com

Richard J. Ladle

richard.ladle@ouce.ox.ac.uk environmental stresses, and discuss the potential scientific and practical applications of this innovative methodology. The recent availability of portable devices has significantly expanded the potential utilization of ChlF techniques, especially for the purposes of crop phenotyping and monitoring.

Keywords Chlorophyll fluorescence - JIP-test .

Photosynthesis · Photosystem II · Quantum efficiency · Stress detection
Abbreviations
ABS Absorption flux
Chl Chlorophyll

1 Department of Plant Physiology, Faculty of Agriculture and Biology, Warsaw University of Life Sciences (WULSSGGW), Nowoursynowska 159, 02-776 Warsaw, Poland

2 School of Life Sciences, Devi Ahilya University, Indore 452 017, MP, India

3 Department of Chemistry and Biochemistry, University of Québec in Montréal, Montréal, QC, Canada

4 Department of Plant Physiology, Slovak University of Agriculture, Tr. A. Hlinku 2, 94976 Nitra, Slovak Republic

5 Racławicka 106, 02-634 Warsaw, Poland

6 Department of Biophysics and Radiobiology, Faculty of Biology, St. Kliment Ohridski University of Sofia, 8 Dr. Tzankov Blvd., 1164 Sofia, Bulgaria

7 School of Geography and the Environment, University of Oxford, South Parks Road, Oxford, UK

8 Institute of Biological Sciences and Health, Federal University of Alagoas, Av. Lourival Melo Mota, s/n, Tabuleiro do Martins, Maceió, Alagoas 57072-900, Brazil 


$\begin{array}{ll}\text { ChlF } & \text { Chlorophyll fluorescence } \\ \text { CS } & \text { Cross section of the sample } \\ \text { Cyt } b_{6} f & \text { Cytochrome } b_{6} f \\ \text { DF } & \text { Delayed (chlorophyll) fluorescence } \\ \text { DFI } & \text { Drought factor index } \\ \text { LHC (II) } & \begin{array}{l}\text { Light-harvesting complex (of PSII) } \\ \text { Oxygen-evolving complex }\end{array} \\ \text { OEC } & \text { Excited PSII reaction center } \\ \text { P680* } & \text { PSI reaction center } \\ \text { P700 } & \text { Photosynthetically active radiation } \\ \text { PAR } & \text { Plastocyanin } \\ \text { PC } & \text { Principal component analysis } \\ \text { PCA } & \text { Prompt (chlorophyll) fluorescence } \\ \text { PF } & \text { Pheophytin } \\ \text { Pheo } & \text { Plastoquinone } \\ \text { PQ } & \text { Photosystem I, II } \\ \text { PSI, PSII } & \text { Primary plastoquinone electron acceptor of } \\ \text { QA } & \text { PSII } \\ & \text { Secondary plastoquinone electron acceptor } \\ \text { Q }_{B} & \text { Reaction center } \\ \text { RC } & \text { Reactive oxygen species } \\ \text { ROS } & \end{array}$

\section{Introduction}

Over the course of the 21 st century, global agriculture must produce more food to sustain a growing human population (Beddington et al. 2012). However, this goal is threatened by anthropogenic climate change which has the potential to dramatically reduce yields in affected regions (Lobell et al. 2008). Recent studies indicate that Chlorophyll fluorescence $(\mathrm{ChlF})$ measurements may provide unique benchmarks to improve global agricultural productivity models, improving the reliability of crop yield projections under climate change scenarios (Guanter et al. 2014; Malaspina et al. 2014). More generally, ChlF is emerging as a very powerful tool in agricultural, environmental, and ecological studies (Gottardini et al. 2014). One of its main advantages is that ChlF is a non-invasive tool, allowing scientists to get information on the photosynthetic process without destroying the tested sample.

Under natural conditions, plants are exposed to many adverse environmental stress factors. These can disrupt the photosynthetic apparatus, causing a decrease of plant productivity and overall yield. Photosynthesis is particularly sensitive to environmental constraints (see Kalaji et al. 2012), making photosynthetic measurements an important component of plant stress studies. However, traditional methods, even technically advanced ones such as the measurements of photosynthetic rates through gas exchange $\left(\mathrm{CO}_{2}, \mathrm{H}_{2} \mathrm{O}\right.$, and $\left.\mathrm{O}_{2}\right)$, are time-consuming and provide incomplete information on overall photosynthetic function. In contrast, ChlF measurements represent a simple, non-destructive, inexpensive and rapid tool for analyzing light-dependent photosynthetic reactions and for indirectly estimating chlorophyll content within the same sample tissue (See reviews by Govindjee 1995; Papageorgiou and Govindjee 2011; and by Stirbet and Govindjee 2011, 2012). These technical advantages of ChlF approaches have made it a popular technique among plant breeders (e.g., for crop phenotyping and monitoring), biotechnologists, plant physiologists, farmers, gardeners, foresters, ecophysiologists, and environmentalists.

Critically, from the perspective of plant stress studies, ChlF measurements also provide indirect information about the physiological condition of plants. Analysis of chlorophyll fluorescence (ChlF) induction curves allows the evaluation of the physiological condition of photosystem II (PSII) and photosynthetic electron transport chain components. It also provides information on the cooperation of light-dependent photochemical reactions and lightindependent biochemical reactions. More generally, $\mathrm{ChlF}$ measurements relate, directly or indirectly, to all stages of light-dependent photosynthetic reactions, including photolysis of water, electron transport, $\mathrm{pH}$ gradient formation across the thylakoid membrane, and ATP synthesis and thus general bioenergetic condition of the photosynthetic machinery (Bernát et al. 2012).

Numerous ChlF techniques and applications have now been developed, each one contributing to knowledge of photosynthesis. In this review, we focus on results from fast fluorescence analysis induced by continuous illumination. These studies were made possible by the development of a reliable mathematical model known as the JIPtest (Strasser et al. 2004) that allowed the analysis of fluorescence changes that occur in less than $1 \mathrm{~s}$. Such analyses provide detailed information on the status and function of PSII reaction centers, antenna, as well as on donor and acceptor sides of PSII. The main focus of the review is to outline the effects of stress factors on the photochemical processes as reflected in changes in fast ChlF kinetics and related biophysical parameters.

\section{Analysis of polyphasic chlorophyll fluorescence kinetics}

Illumination of a dark-adapted photosynthetic sample allows a polyphasic chlorophyll fluorescence induction curve to be obtained (O-J-I-P-transient) (Fig. 1). The curve's trajectory provides considerable information about the structure and function of the photosynthetic apparatus (Kautsky and Hirsch 1931; Schreiber et al. 1994). The JIPtest is based on the rise in polyphasic fast chlorophyll $a$, 


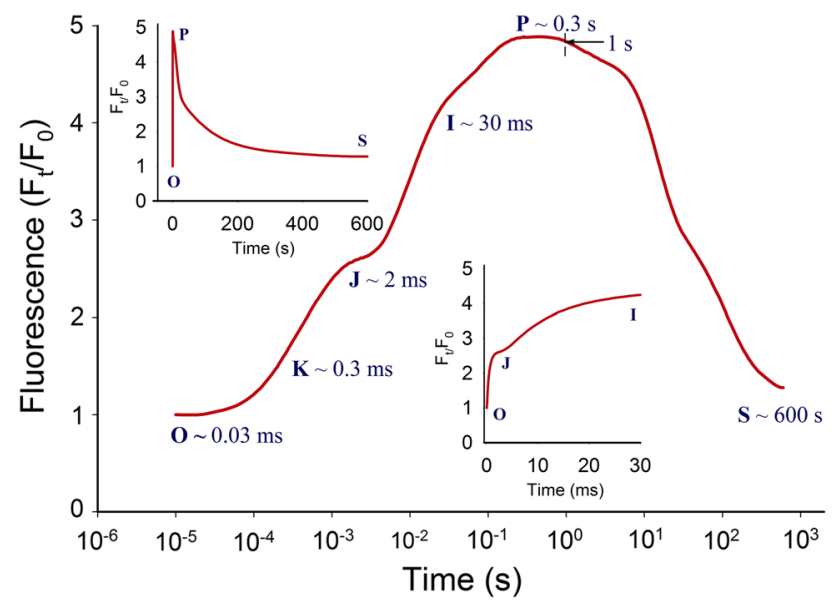

Fig. 1 A typical Chlorophyll $a$ polyphasic fluorescence curve, exhibited by plants (main plot). The transient is plotted on a logarithmic time scale from $10 \mu$ s to $600 \mathrm{~s}$. The same curve plotted in regular time scale is shown in upper insertion (left). Initial part of OJIP transient $(0-30 \mathrm{~ms})$ plotted on regular time scale is shown in second insertion (bottom). The marks refer to the selected time points used by the JIP-test for the calculation of structural and functional parameters. The signals are the fluorescence intensity $F_{\mathrm{o}}$ (at $30 \mu \mathrm{s}$ ); the fluorescence intensity $F_{K}$ (at $300 \mu$ s); the fluorescence intensities $F_{\mathrm{J}}$ (at $2 \mathrm{~ms}$ ) and $F_{\mathrm{I}}$ (at $30 \mathrm{~ms}$ ); the maximal fluorescence intensity, $F_{\mathrm{P}}=F_{\mathrm{M}}$ (at time denoted as $t_{\mathrm{FM}}$ ). Usually, for analysis of fluorescence transient, the record is limited to $1 \mathrm{~s}$, creating typical OJIPpolyphasic fluorescence rise

and is used for investigating the correlation between lightdependent reactions and ChlF. It is based on the theory of "energy flow" across thylakoid membranes (Strasser et al. 2000). This theory can be operationalized in simple algebraic equations, representing the balance between total energy inflows and outflows for each of the examined lightharvesting complexes and providing information on the probable distribution of absorbed energy. With these equations, it is possible to describe the energetic communication (also known as the "grouping" or "connectivity" and "overall grouping probability") between the PSII complexes (Stirbet 2013).

The name of the JIP-test (OJIP) originates from the specific points on the induction curve formed by the recorded ChlF signal (Fig. 1): these correspond to the gradual reduction of $\mathrm{Q}_{A}$ and the primary electron acceptor of PSII. The shape of the curve depends from PSII grouping (L-band) (Tsimilli-Michael and Strasser 2013) and the balance between electron donation from $\mathrm{OEC} \rightarrow \mathrm{P} 680^{+}$and electron accept from $\mathrm{Q}_{\mathrm{A}}^{-}$(K-band) (Strasser et al. 2005). The O-J part of the fluorescence rise relates to the closure of some of the PSII reaction centers in response to the reduction of $Q_{A}$ to a level determined by the ratio between the trapping rate and $\mathrm{Q}_{\mathrm{A}}$ reoxidation rate by $\mathrm{Q}_{\mathrm{B}}$ and the rest of the electron transfer chain. The $\mathrm{J}-\mathrm{I}$ part of the curve corresponds to the reduction of the secondary electron acceptor $\mathrm{Q}_{\mathrm{B}}$, plastoquinone (PQ), cytochrome $\left(\mathrm{Cyt} \mathrm{b}_{6} \mathrm{f}\right)$, and PC. The increase in $\mathrm{ChlF}$ in the I-P part of the induction curve is typically attributed to the reduction of electron transporters (ferredoxin, intermediary acceptors, and NADP) of the PSI acceptor side. Stress conditions such as high temperature, excessive PAR, nitrogen deficiency, or drought inhibit the oxygen-evolving complex (OEC) and block the electron transport between the OEC and tyrosine (Guha et al. 2013). Under stressful conditions, a peak occurs (the K-band) within the 200-300 $\mu$ s range of the ChlF induction curve, indicating a disruption of the OEC.

The JIP-test parameters characterizing the PAR energy absorption and electron transport can be categorized into four main groups: (1) basic measured and calculated values [fluorescence $\left(F_{\mathrm{t}}\right)$ and variable fluorescence $\left(V_{\mathrm{t}}\right)$ values, initial slope, etc.]; (2) quantum yields and probabilities; (3) energy fluxes; and (4) vitality indices. The biophysical parameters representing the energy fluxes are divided into specific and phenomenological. The specific parameters are calculated per reaction center (RC), while the phenomenological parameters are calculated per sample cross section (CS).

The vitality indices represent the products of several independent parameters combining structural and functional criteria. These criteria include the density of reaction centers, the quantum efficiency of primary photochemistry, and conversion of excitation energy in electron transport (Strasser et al. 2000, 2004, 2010; Zushi et al. 2012). The vitality indices were created as non-specific parameters to be used mostly in practical applications, such as screening for enhanced stress tolerance underfield conditions (Srivastava et al. 1999; Strasser et al. 2004; Brestic and Zivcak 2013).

Chlorophyll fluorescence kinetics can also be used to reveal PSII heterogeneity of photosynthetic apparatus. PSII is naturally heterogeneous in terms of antenna and reducing side. Antenna heterogeneity includes variations in antenna size and in connectivity (grouping) of antenna molecules. Based on antenna size, PSII centers have been classified as alpha $(\alpha)$, beta $(\beta)$, and gamma $(\gamma)$ (Melis and Homann 1976). These differ from each other in life span and number of associated chlorophylls. Reducing side heterogeneity is related to the ability to transfer an electron from $\mathrm{Q}_{\mathrm{A}}$. Centers which are capable of transferring electrons from $\mathrm{Q}_{\mathrm{A}}$ to $\mathrm{Q}_{\mathrm{B}}$ are termed $\mathrm{Q}_{\mathrm{B}}$ reducing centers, while those which are unable to do so are termed $\mathrm{Q}_{\mathrm{B}}$ non-reducing centers. Specific characteristics of PSII heterogeneity have been reviewed in Jajoo (2013). Recent studies have shown changes in PSII heterogeneity under high temperature (Mathur et al. 2011b), high salt (Mehta et al. 2010a), and some pollutants like polycyclic aromatic hydrocarbons (PAH) (Tomar and Jajoo 2013, 2014). Changes may relate to the number of active/inactive reaction centers, 
interconversion of active alpha centers into inactive beta and gamma centers, and increases in the number of $Q_{B}$ non-reducing centers under various stress conditions.

\section{Chlorophyll fluorescence kinetic parameters in response to various abiotic stresses}

In the following sections, we review the evidence that $\mathrm{ChlF}$ kinetics may serve as an useful indicator of the negative impacts of climate change and human activities, such as high and low temperature, drought, salinity, nutrient deficiencies, and heavy metals.

\section{Temperature effects}

Climate change is likely to increase heat stress in plants, limiting productivity and biomass production. Photosynthesis is the most sensitive of plant cell processes to high temperatures (Sharkey and Schrader 2006), which cause changes in the reduction-oxidation properties of PSII acceptors and reduce the efficiency of photosynthetic electron transport in both photosystems (Mathur et al. 2014).

Heat stress affects the values of ChlF parameters (Fig. 2a). For example, in response to high temperature stress apples Malus x domestica Borkh reduced both the ratio of reduced acceptors (plastoquinone) $\mathrm{Q}_{\mathrm{A}}^{-}$to $\mathrm{RC}$ and the ratio of reduced acceptors (plastoquinone) $\mathrm{Q}_{\mathrm{B}}^{-}$to $\mathrm{Q}_{\mathrm{A}}^{-}$. There was also a decrease in the maximum quantum yield of PSII and an increase in the minimal fluorescence value (Chen et al. 2009; Brestic et al. 2013). High temperature stress also influences the shape of the O-J-I-P curve, decreasing $F_{\mathrm{M}}$ and increasing $F_{\mathrm{o}}$. The increase in $F_{\mathrm{o}}$ may be due to the release of LHC II from the PSII complex, inactivation of PSII photochemical reaction or an inhibition of electron flow due to the reduced transfer of $Q_{A}$ to $Q_{B}$ (Mathur et al. 2011a). For example, the increase of $F_{o}$ observed in spinach and rice has been attributed to the irreversible dissociation of LHC II from the PSII complex and partly reversible inactivation of PSII (Yamane et al. 1997). The decrease in the fluorescence $F_{\mathrm{M}}$ level may be related to denaturation of chlorophyll-proteins (Yamane et al. 1997).

The $\mathrm{K}$ peak (at $300 \mu \mathrm{s}$ ) is a well-documented symptom of heat stress, and is thought to indicate the separation of the OEC complex and electron transport between pheophytin and primary electron acceptor $\mathrm{Q}_{\mathrm{A}}$ (Strasser et al. 2000; Lazár 2006). In wheat, a treatment at $35^{\circ} \mathrm{C}$ had no affect on photosynthetic efficiency, while exposure to $45^{\circ} \mathrm{C}$ caused irreversible damage to the OEC (Schreiber et al. 2012). The direct cause of the ChlF curve peak (K) is the outflow of electrons from P680 to PSII acceptors, which over-compensates the inflow of electrons from the donor side of PSII to P680. The $\mathrm{K}$ peak is also affected by changes in the energetic relationships between photosystems II. An increase in the $F_{\mathrm{K}} / F_{\mathrm{J}}$ ratio (Srivastava and Strasser 1995) indicates that the heat stress is inhibiting the donation of electrons by the OEC.

The fast ChlF technique also represents a useful tool to monitor PSII thermostability. The most efficient approach is to estimate the critical temperature, i.e., the threshold level above which there is a sharp increase/decrease of the observed parameter (Brestic and Zivcak 2013). Some genotypes can serve as donors of enhanced heat tolerance in crop breeding programs. For example, the response of heat-treated common bean (Phaseolus vulgaris L.) lines and their recovery were monitored by changes in ChlF induction and analyzed by means of the JIP-test (Stefanov et al. 2011). PSII thermostability of 30 genotypes of Winter wheat plants (Triticum aestivum L.) with different geographic origins were identified using the fast ChlF kinetics (Brestic et al. 2012). ChlF has also been shown to be a more effective than conventional methods (e.g., harvest index, grain filling, etc.) for screening genotypes of durum wheat (Gautum et al. 2014).

In certain latitudes, low temperatures are a major factor limiting crop yields (Yang et al. 2009). In the northern hemisphere, low temperatures during the winter and early spring are usually followed by intense PAR. These conditions can cause degradation of the thylakoid structure and distortion in light-dependent photosynthetic reactions (Suzuki et al. 2011). Cold stress also affects ChlF parameters (Fig. 2b). For example, a decrease was observed in chlorophyll content, OEC efficiency on the donor side of PSII, photochemical quenching, and efficiency of open PSII reaction centers for bitter melon plants (Momordica charantia L.) exposed to cold stress (Yang et al. 2009). Some plant species are known for their tolerance to low temperatures, showing less photoinhibition of PSII. For example, under cold stress pea plants show only small modifications in ChlF parameters (Strauss et al. 2006; Streb et al. 2008).

\section{Drought stress}

Drought stress effects on photosynthetic apparatus are well known. They typically start with mostly stomatal effects at moderate drought intensity, and culminate in metabolic and structural changes caused by severe or long-lasting drought stress (Jedmowski et al. 2013). This final changes are also associated with enhancement of photoprotective and antioxidant functions and pathways (Chaves et al. 2009). PSII has high resistance to water deficit (compared to PSI) and negative impacts therefore only occur under conditions of extreme drought (Lauriano et al. 2006). 

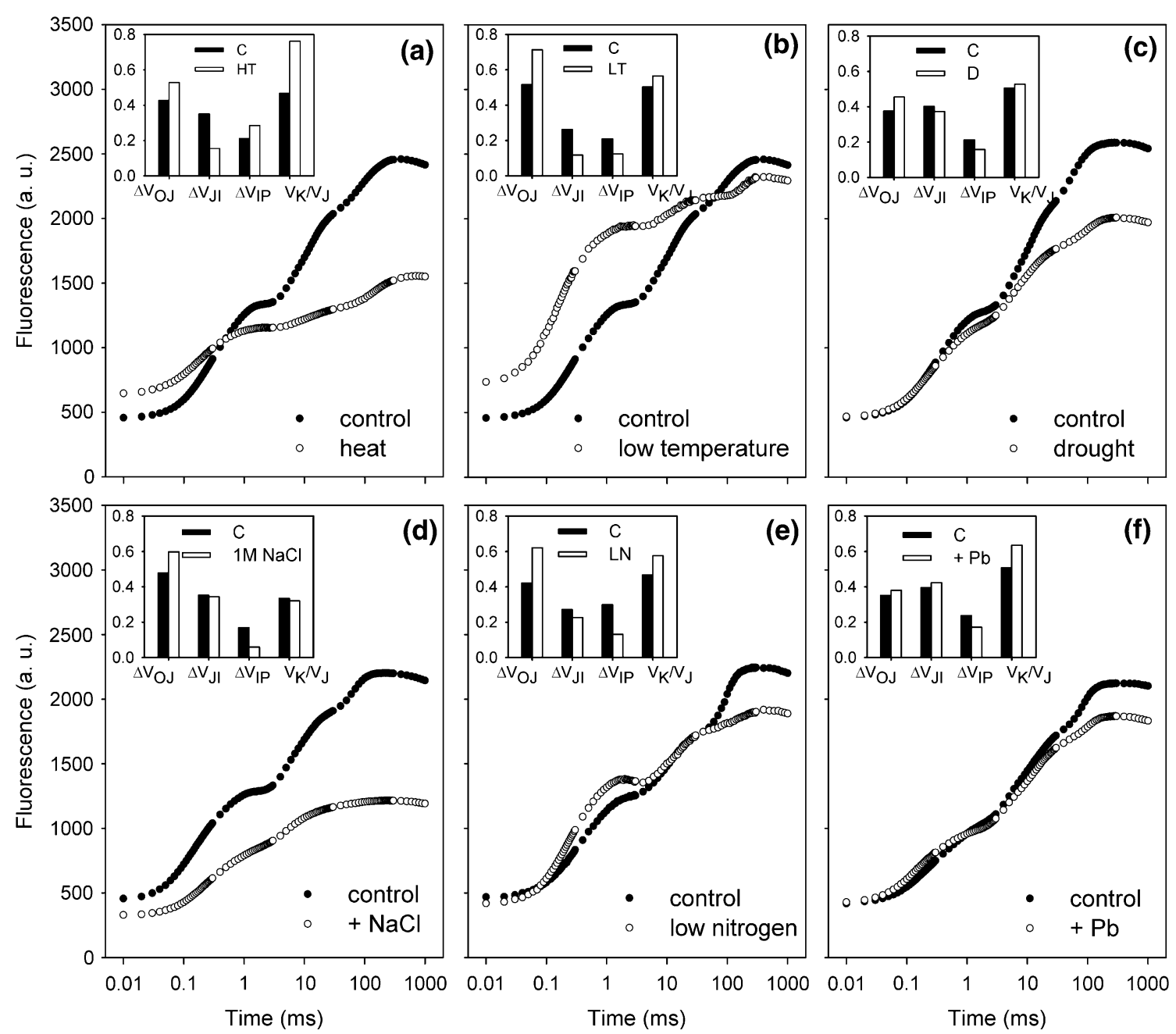

Fig. 2 The $\mathrm{O}(\mathrm{K}) \mathrm{JIP}$-transients of chlorophyll fluorescence in wheat (Triticum sp. L.) plant samples exposed to different stress conditions compared to non-stressed plants. The insertions show the changes of amplitude of relative variable fluorescence in $\mathrm{O}-\mathrm{J}$ phase $\left(\Delta V_{\mathrm{OJ}}\right), \mathrm{J}-\mathrm{I}$ phase $\left(\Delta V_{\mathrm{JI}}\right)$, I-P phase $\left(\Delta V_{\mathrm{IP}}\right)$ and of the ratio of variable fluorescence in time $0.3 \mathrm{~ms}\left(V_{\mathrm{K}} / V_{\mathrm{J}}\right)$ to variable fluorescence in time $2 \mathrm{~ms}\left(V_{\mathrm{J}}\right)$ as an indicator of the PSII donor side limitation (K-band). Individual graphs present comparisons of records in non-stressed

plants (control, C) of a exposed to heat stress ( $8 \mathrm{~h}$ exposed to high temperature in moderate actinic light, the leaf temperature was $\sim 40{ }^{\circ} \mathrm{C}$ ); b exposed to long-lasting suboptimal low temperature (10 days at $10 / 6{ }^{\circ} \mathrm{C}$ day/night); $\mathbf{c}$ exposed to severe drought stress (12th day after withholding of irrigation, leaf relative water content $\sim 60 \%$ ); d exposed to salt $(\mathrm{NaCl})$ stress; e plants cultivated at low soil nitrogen content (low nitrogen, LN); and $\mathbf{f}$ exposed to lead $(\mathrm{Pb})$. Data were provided by the authors of this review

ChlF measurements indicate enhanced protection of PSII and PSI photochemistry under drought conditions by adjusting the energy distribution between photosystems and by activating alternative electron sinks (Zivcak et al. 2013). Drought stress may enhance the resistance of PSII to heat stress as shown by the disappearance of the K-band from the OJIP transient (see Fig. 2c and Oukarroum et al. 2012).

The ChlF method is potentially useful for screening genotypes for drought tolerance (Guha et al. 2013). The fluorescence rise during the first $2-3 \mathrm{~ms}$ is related to primary photochemistry and it has been suggested that stimulated L- and K-bands can be used as tools for evaluating potential to cope with (and recover from) drought stress (Oukarroum et al. 2007). The L-band is influenced by the excitation energy transfer between PSII units, commonly denoted as connectivity or grouping (Strasser and Stirbet 1998).This can be influenced composition of PSII antennae that have been changed due to mutations (Brestic et al. 2014) or environmental conditions (Zivcak et al. 2014a). The K-band has been associated with a dissociation of the oxygen-evolving complex (OEC) (Guissé et al. 1995). The measurement of OLKJIP fluorescence transients and their analysis using the JIP-test might therefore be used as indicators for drought stress tolerance and physiological disturbances before the appearance of visible signs of drought stress.

The most widely used parameter from the ChlF OJIP transient is the performance index (PI), which provides 
quantitative information about the general state of plants and their vitality. PI is the product of three independent characteristics: the concentration of reaction centers per chlorophyll, a parameter related to primary photochemistry and a parameter related to electron transport (Strasser et al. 2004). PI is therefore sensitive to changes in either antenna properties, trapping efficiency or electron transport beyond $\mathrm{Q}_{\mathrm{A}}$. For example, the PI of winter wheat decreased during prolonged post-anthesis drought stress. Moreover, the drought tolerance of wheat genotypes estimated from PI values recorded in drought stress also correlated well with the drought tolerance assessed by grain yield (Zivcak et al. 2008). PI is closely related to the drought factor index (DFI), which represents the relative drought-induced reduction of PI during a freely defined time of drought stress. A DFI approach was used by Strauss et al. (2006) to detect dark chilling tolerance in soybean genotypes. DFI has also been used to rank drought stress tolerance in 10 barley varieties (Oukarroum et al. 2007) and 21 mutant germplasms of sesame (Boureima et al. 2012). The most tolerant and the most sensitive races of barley and Sorghum bicolor from Egypt were identified using the PI parameter and the ChlF fast induction curve (Jedmowski et al. 2013). These studies demonstrate that drought-tolerant and drought-sensitive cultivars can be differentiated at the level of PSII. An increase of ABS/RC ratio under drought stress has also been observed (Van Heerden et al. 2007; Gomes et al. 2012), possibly due to inactivation of some PSII RCs or an increase in antenna size.

Drought stress can also affect the relative amplitude of the I-P phase from OJIP curve. The I-P phase has been recorded as the slowest phase of the fluorescence rise (approximately 30-200 ms) and was parallel the re-reduction of plastocyanin $\mathrm{PC}^{+}$and $\mathrm{P}_{700}{ }^{+}$in PSI (Schreiber et al. 1989; Schansker et al. 2003). The I-P phase seems to be related to the content of PSI reaction centers (Ceppi et al. 2012) or availability of linear electron transport as determined by 820 -nm transmission measurements (Zivcak et al. 2014a). For example, the extent of the I-P loss in barley varieties depends on their drought tolerance (Oukarroum et al. 2009; Ceppi et al. 2012). ChlF is emitted following a dark-to-light transition of a photosynthetic sample, while delayed fluorescence emission (DF) occurs during light-to-dark transitions (Goltsev et al. 2009; Strasser et al. 2010; Kalaji et al. 2012). DF is thought to reflect the recombination (in the dark) between the reduced primary electron acceptor $\mathrm{Q}_{\mathrm{A}}^{-}$and the oxidized donor $\left(\mathrm{P} 680^{+}\right)$of PSII that are formed after light-induced charge separation. The shape of the DF induction curve depends on the sample type and its physiological state. Simultaneous measurements of Chl $a$ fluorescence and DF have recently been developed to obtain rate constants for different photosynthetic reactions (Strasser et al. 2010). Using this technique, Goltsev et al. (2012) observed that reoxidation of $\mathrm{Q}_{\mathrm{A}}^{-}$was inhibited during drought stress and that quantum yields of photoinduced electron transport in PSII reaction center to $\mathrm{Q}_{\mathrm{A}}$ were suppressed and that the fast phase of photoinduced kinetics of the modulated reflection signal was reduced.

\section{Salinity stress}

Plant responses to salinity stress are determined by many aspects, such as the expression of specific genes, plant development stage, and glycine betaine accumulation which protects the photosynthetic apparatus by stabilizing the external proteins of the PSII complex (Murata et al. 1992). Salinity stress disrupts the electron transport from the RCs to the plastoquinone pool (Strasser et al. 2000; and Fig. 2d). Schreiber et al. (1994) identified the OEC as one of the most sensitive components in the photosynthetic electron transport chain. Its reduced performance is usually caused by an electron transport disorder. Modifications can also be observed in ChlF parameters and PSII functioning. Under high salinity conditions, electron trapping in PSII reaction center becomes less efficient due to the dissociation of LHCII and PSII (Havaux 1993). A decrease in maximum quantum yield of PSII and an increase in nonphotochemical quenching have been recorded in a number of species, including barley (Kalaji and Rutkowska 2004), cultivated tobacco Nicotiana tobacum L. (Yang et al. 2008), and even among certain halophytes, such as Sarcocornia fruticosa $\mathrm{L}$. Moreover, in tomatoes and cucumber Cucumis sativus L. seedlings the following parameters were reduced during salinity stress: PSII efficiency in light, electron transport chain efficiency, and the efficiency of PSII open reaction centers in light (He et al. 2009; Zhang and Sharkey 2009). The damage caused by salinity stress in wheat was more prominent at the donor side rather than the acceptor side of PSII, and this damage was fully reversible $(\sim 100 \%)$ at the acceptor side of PSII, while recovery of the donor side was less than $85 \%$ (Mehta et al. 2010b). The osmotic and ionic effects of salinity stress have also been differentiated using ChlF measurements (Singh-Tomar et al. 2012).

\section{Nutrient deficiency stress}

Deficiency in specific nutrients ( $\mathrm{N}, \mathrm{P}, \mathrm{K}, \mathrm{Ca}, \mathrm{Mg}, \mathrm{S}$, or $\mathrm{Fe}$ ) disrupts the functioning of the photosynthetic apparatus, decreasing PSII photochemical efficiency and modifying the values of ChlF parameters (Smethurst et al. 2005). Nitrogen $(\mathrm{N})$ accessibility is the key factor limiting the growth of plants, being a component of all proteins and nucleic acids and other organic compounds. $\mathrm{N}$ deficiency modifies thylakoid membranes and disrupts their 
functioning (Fig. 2e), leading to acceleration of chloroplast aging and plastoglobule formation (Wu et al. 2006). Nitrogen is also an important element in RuBisCO photosynthetic complexes, the Calvin-Benson cycle enzymes, chlorophyll, and carotenoids (Correia et al. 2005). Nitrogen deficiency contributes to reductions in transpiration, stomatal conductance, the chlorophyll and carotenoids content, and the concentration of soluble sugars (Huang et al. 2004). Insufficient nitrogen uptake also reduces the electron acceptor pool in PSII and decreases RuBisCO and phosphoenolpyruvate carboxylase (PEPCase) activity (Correia et al. 2005).

JIP-test analyses have been applied several times in studies dealing with nitrogen deficiency and the effects of poor nitrogen supply on PSII has been well described (Redillas et al. 2011, Li et al. 2012). Specifically, N deficiency led to a significant decrease of the density of reaction centers (Dudeja and Chaudhary 2005). Conversely, the positive effects of higher nitrogen treatments on PI values have been documented in soybean (van Heerden et al. 2004), maize (Li et al. 2012), and wheat (Zivcak et al. 2014b).

Phosphorus (P) is also essential for plant growth and development. Major deficits cause modifications in grain and thylakoid structure and in light-harvesting complexes absorbing PAR, thereby reducing PSII activity (Foyer and Spencer 1986). P deficiency also has a negative impact on NADPH regeneration, reduces the quantum yield and carboxylic efficiency of photosynthesis and the electron transport efficiency (Wu et al. 2006). The JIP-test has been successfully used to estimate the activity/efficiency of PSII in plants exposed to phosphorus deficiency stress (Kruger et al. 1997; Tsimilli-Michael and Strasser 2008). Indeed, various studies have demonstrated a correlation between JIP-test parameters and gas exchange orplant growth parameters (Strasser et al. 2000).

Potassium $(\mathrm{K})$ plays a key role in cellular osmoregulation: its ions are necessary to retain the $\mathrm{pH}$ gradient across the thylakoid membrane (Rampino et al. 2006). P deficiency increases stomatal conductance resistance, limiting carbon dioxide diffusion through the stomata. In photosynthesis, potassium's role in the activation of numerous enzymes and in ATP synthesis is probably much more significant than its role in controlling stomatal functioning. However, little is known about the impact of P deficiency on photosynthetic apparatus efficiency and PSII functioning. Nevertheless, a decrease in values of some photosynthetic parameters, such as electron transport efficiency and maximum quantum yield of PSII, has been observed under $P$ deficiency (Schweiger et al. 1996).

There are numerous studies that have used prompt $\mathrm{ChlF}$ parameters to analyze the effects on photochemical functions of other mineral deficiencies, such as calcium (Liu et al. 2009; Lauriano et al. 2006), magnesium (Smethurst et al. 2005), and iron (Molassiotis et al. 2006). As many nutrients have specific effects on PSII photochemistry, the question here is whether it is possible to identify nutrient deficiencies using chlorophyll fluorescence kinetics. Although this issue remains open, Kalaji et al. (2014a, b) were able to recognize deficiencies of the main nutrients in tomato using principal component analysis of data derived from prompt ChlF analysis.

\section{Heavy metal stress}

High levels of heavy metals disrupt the photosynthesis process, but the impact of particular heavy metal ions may be species specific (Antosiewicz 2005; Mishra and Dubey 2005). Photosystem I (PSI) is considered more tolerant of heavy metal impact than PSII (Romanowska et al. 2006; Tuba et al. 2010).

Cadmium $(\mathrm{Cd})$ is one of the most toxic heavy metals and can accumulate in living organisms. Sources of $\mathrm{Cd}$ in the environment include phosphate fertilizers and industrial waste products (Romanowska et al. 2006; Kalaji and Łoboda 2007). However, Cd does not appear to affect the amount of photosynthetic pigments: research on oilseed rape Brassica napus L. seedlings grown in the presence of $\mathrm{Cd}$ for 2 weeks revealed no significant changes to the content of chlorophyll a, chlorophyll $\mathrm{b}$, and carotenoids (Janeczko et al. 2005). Nevertheless, Cd does have a negative impact on the photochemical efficiency of the photosynthetic process. PSII is more sensitive to its impact than the PSI, indicating that $\mathrm{Cd}$ disrupts the PSII functions with greater intensity (Mallick and Mohn 2003). Cd affects both the donor and acceptor sides of PSII. On the donor side, it inhibits the OEC, while on the acceptor site it inhibits electron transport between $\mathrm{Q}_{\mathrm{A}}{ }^{-}$and $\mathrm{Q}_{\mathrm{B}}{ }^{-}$(Sigfridsson et al. 2004). Disruption of the electron transport chain is due to degradation of the LHCII oligomer. The presence of $\mathrm{Cd}$ ions also increases the heat dissipation of excitation energy-defined as non-photochemical quenching (Janeczko et al. 2005). A detailed analysis of ChlF records from oilseed rape revealed that $\mathrm{Cd}$ caused a decrease in specific energy flow per sample cross section. Specifically, decreases in RC/CS, $\mathrm{ET}_{\mathrm{O}} / \mathrm{CS}$, and in the activity of OEC were observed (Janeczko et al. 2005). $\mathrm{F}_{\mathrm{V}} /$ $\mathrm{F}_{\mathrm{M}}$ appears to be the least sensitive $\mathrm{Cd}$ impact parameter, indicating the maximum quantum yield of PSII. Plant resistance to $\mathrm{Cd}$ is associated with the ability of "sweeping" ROS, launching protective mechanisms such as activation of antioxidant enzymes, in particular peroxidase (Ekmekçi et al. 2008), and the synthesis of antioxidantactive compounds, e.g., glutathione (Streb et al. 2008).

Lead $(\mathrm{Pb})$ also has harmful effects on plants. The main sources of $\mathrm{Pb}$ in soil and plants are gas emissions from 
coal-fueled power plants, fuel gases, and industrial technology (Mishra and Dubey 2005). Pb causes modification of respiration and increases ATP and the ATP/ADP ratio, a result of mitochondrial production of this high-energy compound (Romanowska et al. 2002). The decrease in the efficiency of photosynthesis in plants under $\mathrm{Pb}$ stress is a result of disruption of chloroplast ultrastructure and thylakoid membrane lipid composition, and a reduction of synthesis of chlorophyll and carotenoids (Sharma and Dubey 2005). Pb interrupts the uptake of nutrients (such as magnesium and iron) which, in turn, are essential for photosynthesis. Moreover, it causes the dissociation of the polypeptides OEC and the removal of $\mathrm{Ca}, \mathrm{Cl}$, and $\mathrm{Mn}$ compounds from this complex (Sharma and Dubey 2005; Romanowska et al. 2006). The intensities of fluorescence at $\mathrm{I}$ and $\mathrm{P}$ steps in the $\mathrm{O}-\mathrm{J}-\mathrm{I}-\mathrm{P}$ induction curve of plants exposed to $\mathrm{Pb}$ stress decreased in relation to the control (Fig. 2f), and a peak (K) occurred (Kalaji and Łoboda 2007). The appearance of this point on the ChlF induction curve may be associated with electron transport inhibition between the OEC and the PSII reaction center (Strasser et al. 2004; Wu et al. 2008). Models of Pb stress suggest that energy absorption and dissipation within the PSII are high, while electron trapping and transport are reduced (Lazár and Jablonský 2009).

\section{Limitations of prompt ChlF methods}

Mathematical models for analysis of prompt ChlF kinetics, such as JIP-test, were developed exclusively as a biophysical tool for assessment of the cascade of chloroplast redox reactions at microsecond or millisecond scales. Nevertheless, even early studies generated interesting empirical knowledge on the relationship between the physiological status of the sample and the shape of fluorescence transient (Strasser et al. 2000). There have subsequently been many articles documenting the direct relationship between the physiological status of leaves and prompt $\mathrm{ChlF}$ transient. This reflects the fact (often neglected) that the measured signal is the mixture of many signals (see paragraph on PSII heterogeneity above) related to processes associated with adjusting of structure and function of photosynthetic apparatus to current metabolic needs or environmental conditions. Thus, several factors need to be carefully monitored to avoid erroneous and over-simplified interpretations (Evans 2009).

The simplicity and rapidity of the method together with misunderstanding of the basic principles has also led to incorrect applications. The use of integrative parameters such as performance index (PI) can be more useful than complex of specific biophysical parameters, which require a deeper understanding of photochemical processes to interpret the data correctly. Pros and Cons of the analysis of the OJIP transient by the so-called JIP-test are well discussed by Stirbet and Govindjee (2011). To avoid the mistakes in ChlF applications, all users are strongly encouraged to be familiar with practical aspects of measurements (reviewed in Kalaji et al. 2014a).

\section{Concluding remarks}

This review paper brings up-to-date information on the vast opportunities of the application of chlorophyll fluorescence technique in plant science, agricultural and ecological research. Measured signals of chlorophyll fluorescence and its statistical analysis (e.g., by JIP-test) can be used to predict, monitor, and identify stress in plants. Consequently, it could be applied in almost any ecological study of plants as a bioindicator. The versatility of ChlF measurements means they can be applied at the level of a single plant to grassland, cropland, and even marine ecosystems. However, this potential versatility emphasizes the need for more practical and conceptual studies that would allow scientists to draw reliable information about plant growth and health. Such an approach would not only lead to improvements in our understanding of the physiological basis of photosynthesis but could also contribute to efforts to understand and remediate the impacts of climate change on crop yields and food security.

Author contribution statement Kalaji M. H. and Jajoo A. created the idea of the manuscript and put the first items to be considered in this paper. Moreover, they edited the main lines of the text. Samborska I. A., Cetner M. D., and Łukasik I. developed the initial work suggested by the first two co-authors and added proper details and examples. Brestic M., Zivcak M., Oukarroum A., and Goltsev V. enhanced the text by adding the proper references, figures, and built up the discussion in this manuscript. Richard $\mathrm{J}$. Ladle provided professional (biological) language corrections. We confirm that, all above-listed co-authors contributed equally to this work.

Acknowledgments The authors thank Prof. Govindjee for supporting the idea of this paper, reading, and commenting on the draft of this paper.

Open Access This article is distributed under the terms of the Creative Commons Attribution 4.0 International License (http://crea tivecommons.org/licenses/by/4.0/), which permits unrestricted use, distribution, and reproduction in any medium, provided you give appropriate credit to the original author(s) and the source, provide a link to the Creative Commons license, and indicate if changes were made. 


\section{References}

Antosiewicz DM (2005) Study of calcium-dependent lead-tolerance on plants differing in their level of Ca-deficiency tolerance. Environ Pollut 134(1):23-34

Beddington J, Asaduzzaman M, Clark M, Bremauntz AF, Guillou M, Howlett D, Jahn M, Lin E, Mamo T, Negra C (2012) What next for agriculture after Durban? Science 335:289-290

Bernát G, Schreiber U, Sendtko E, Stadnichuk IN, Rexroth S, Rögner M, Koenig F (2012) Unique properties vs. common themes: the atypical cyanobacterium Gloeobacter violaceus PCC 7421 is capable of state transitions and blue-light-induced fluorescence quenching. Plant Cell Physiol 53(3):528-542

Boureima S, Oukarroum A, Diouf M, Cisse N, Van Damme P (2012) Screening for drought tolerance in mutant germplasm of sesame (Sesamum indicum) probing by chlorophyll $a$ fluorescence. Environ Exp Bot 81:37-43

Brestic M, Zivcak M (2013) PSII Fluorescence techniques for measurement of drought and high temperature stress signal in crop plants: protocols and applications. Molecular stress physiology of plants. Springer, Berlin, pp 87-131

Brestic M, Zivcak M, Kalaji MH, Carpentier R, Allakhverdiev SI (2012) Photosystem II thermostability in situ: environmentally induced acclimation and genotype-specific reactions in Triticum aestivum L. Plant Physiol Biochem 57:93-105

Brestic M, Zivcak M, Olsovska K, Repkova J (2013) Involvement of chlorophyll $a$ fluorescence analyses for identification of sensitiveness of the photosynthetic apparatus to high temperature in selected wheat genotypes. Photosynthesis research for food, fuel and the future. Springer, Berlin, pp 510-513

Brestic M, Zivcak M, Olsovska K, Shao HB, Kalaji MH, Allakhverdiev SI (2014) Reduced glutamine synthetase activity plays a role in control of photosynthetic responses to high light in barley leaves. Plant Physiol Biochem 81:74-83. doi:10.1016/j. plaphy.2014.01.002

Ceppi MG, Oukarroum A, Çiçek N, Strasser RJ, Schansker G (2012) The IP amplitude of the fluorescence rise OJIP is sensitive to changes in the photosystem I content of leaves: a study on plants exposed to magnesium and sulfate deficiencies, drought stress and salt stress. Physiol Plant 144(3):277-288

Chaves MM, Flexas J, Pinheiro C (2009) Photosynthesis under drought and salt stress: regulation mechanisms from whole plant to cell. Ann Bot 103(4):551-560

Chen LS, Li P, Cheng L (2009) Comparison of thermotolerance of sun-exposed peel and shaded peel of 'Fuji'apple. Environ Exp Bot 66(1):110-116

Correia CM, Pereira JMM, Coutinho JF, Björn LO, Torres-Pereira JMG (2005) Ultraviolet-B radiation and nitrogen affect the photosynthesis of maize: a Mediterranean field study. Eur J Agron 22(3):337-347

Dudeja SS, Chaudhary P (2005) Fast chlorophyll fluorescence transient and nitrogen fixing ability of chickpea nodulation variants. Photosynthetica 43:253-259

Ekmekçi Y, Tanyolac D, Ayhan B (2008) Effects of cadmium on antioxidant enzyme and photosynthetic activities in leaves of two maize cultivars. J Plant Physiol 165(6):600-611

Evans JR (2009) Potential errors in electron transport rates calculated from chlorophyll fluorescence as revealed by a multilayer leaf model. Plant Cell Physiology 50(4):698-706

Foyer C, Spencer C (1986) The relationship between phosphate status and photosynthesis in leaves. Planta 167(3):369-375

Gautum A, Agrawal D, SaiPrasad SV, Jajoo A (2014) A quick method to screen high and low yielding wheat cultivars exposed to high temperature. Physiol Mol Biol Plants. doi:10.1007/s12298-014$0252-4$
Goltsev V, Zaharieva I, Chernev P, Kouzmanova M, Kalaji MH, Yordanov I, Krasteva V, Alexandrov V, Stefanov D, Allakhverdiev SI, Strasser RJ (2012) Drought-induced modifications of photosynthetic electron transport in intact leaves: analysis and use of neural networks as a tool for a rapid non-invasive estimation. Biochim Biophys Acta 1817:1490-1498

Goltsev V, Zaharieva I, Chernev P, Strasser RJ (2009) Delayed chlorophyll fluorescence as a monitor for physiological state of photosynthetic apparatus. Biotechnol Biotechnol Equip 23 (Special Edition):452-457

Gomes MTG, da Luz AC, dos Santos MR, Batitucci MDCP, Silva DM, Falqueto AR (2012) Drought tolerance of passion fruit plants assessed by the OJIP chlorophyll $a$ fluorescence transient. Sci Hortic 142:49-56

Gottardini E, Cristofori A, Cristofolini F, Nali C, Pellegrini E, Bussotti F, Ferretti M (2014) Chlorophyll-related indicators are linked to visible ozone symptoms: evidence from a field study on native Viburnum lantana L. plants in northern Italy. Ecol Ind 39:65-74

Govindjee (1995) Sixty-three years since Kautsky: chlorophyll $a$ fluorescence. Aus J Plant Physiol 22:131-160

Guanter L, Zhang Y, Jung M, Joiner J, Voigt M, Berry JA, Frankenberg C, Huete AR, Zarco-Tejada P, Lee JE (2014) Global and timeresolved monitoring of crop photosynthesis with chlorophyll fluorescence. Proc Natl Acad Sci 111(14):E1327-E1333

Guha A, Sengupta D, Reddy AR (2013) Polyphasic chlorophyll $a$ fluorescence kinetics and leaf protein analyses to track dynamics of photosynthetic performance in mulberry during progressive drought. J Photochem Photobiol B 119:71-83

Guissé B, Srivastava A, Strasser RJ (1995) Effects of high temperature and water stress on the polyphasic chlorophyll $a$ fluorescence transient of potato leaves. In: Mathis $\mathrm{P}$ (ed) Photosynthesis: from light to biosphere. Kluwer Academic Publishers, Dordrecht, pp 913-916

Havaux M (1993) Rapid photosynthetic adaptation to heat stress triggered in potato leaves by moderately elevated temperatures. Plant Cell Environ 16(4):461-467

He Y, Zhu Z, Yang J, Ni X, Zhu B (2009) Grafting increases the salt tolerance of tomato by improvement of photosynthesis and enhancement of antioxidant enzymes activity. Environ Exp Bot 66(2):270-278

Huang ZA, Jiang DA, Yang Y, Sun JW, Jin SH (2004) Effects of nitrogen deficiency on gas exchange, chlorophyll fluorescence, and antioxidant enzymes in leaves of rice plants. Photosynthetica 42(3):357-364

Jajoo A (2013) Changes in photosystem II in response to salt stress. Ecophysiology and responses of plants under salt stress. Springer, Berlin, pp 149-168

Janeczko A, Koscielniak J, Pilipowicz M, Szarek-Lukaszewska G, Skoczowski A (2005) Protection of winter rape photosystem 2 by 24 -epibrassinolide under cadmium stress. Photosynthetica 43(2):293-298

Jedmowski C, Ashoub A, Brüggemann W (2013) Reactions of Egyptian landraces of Hordeum vulgare and Sorghum bicolor to drought stress, evaluated by the OJIP fluorescence transient analysis. Acta Physiologiae Plantarum 35(2):345-354

Kalaji MH, Rutkowska A (2004) Reactions of photosynthetic apparatus of maize seedlings to salt stress. Zesz Probl Post NaukRol 496:545-558

Kalaji MH, Carpentier R, Allakhverdiev SI, Bosa K (2012) Fluorescence parameters as early indicators of light stress in barley. J Photochem Photobiol B 112:1-6

Kalaji MH, Schansker G, Ladle RJ, et al (2014a) Frequently asked questions about in vivo chlorophyll fluorescence: practical issues. Photosynth Res. doi: 10.1007/s11120-014-0024-6 
Kalaji MH, Oukarroum A, Alexandrov V, Kouzmanova M, Brestic M, Zivcak M, Goltsev V (2014b) Identification of nutrient deficiency in maize and tomato plants by in vivo chlorophyll $a$ fluorescence measurements. Plant Physiol Biochem. doi:10. 1016/j.plaphy.2014.03.029

Kautsky H, Hirsch A (1931) NeueVersuchezur Kohlensaureassimilation. Naturwissenschaften 19:964

Kruger GHJ, Tsimilli-Michael M, Strasser RJ (1997) Light stress provokes plastic and elastic modifications in structure and function of photosystem II in camellia leaves. Physiol Plant 101:265-277

Lauriano JA, Ramalho JC, Lidon FC, Céumatos M (2006) Mechanisms of energy dissipation in peanut under water stress. Photosynthetica 44(3):404-410

Lazár D (2006) The polyphasic chlorophyll $a$ fluorescence rise measured under high intensity of exciting light. Funct Plant Biol 33(1):9-30

Lazár D, Jablonský J (2009) On the approaches applied in formulation of a kinetic model of photosystem II: different approaches lead to different simulations of the chlorophyll $a$ fluorescence transients. J Theor Biol 257(2):260-269

Li G, Zhang ZS, Gao HY, Liu P, Dong ST, Zhang JW, Zhao B (2012) Effects of nitrogen on photosynthetic characteristics of leaves from two different stay-green corn (Zea mays L.) varieties at the grain-filling stage. Can J Plant Sci 92:671-680

Liu WJ, Chen YE, Tian WJ, Du JB, Zhang ZW, Xu F, Zhang F, Yuan S, Lin HH (2009) Dephosphorylation of photosystem II proteins and phosphorylation of CP29 in barley photosynthetic membranes as a response to water stress. Biochim Biophys Acta 1787(10):1238-1245

Lobell DB, Burke MB, Tebaldi C, Mastrandrea MD, Falcon WP, Naylor RL (2008) Prioritizing climate change adaptation needs for food security in 2030. Science 319:607-610

Łoboda T, Kalaji MH (2007) Photosystem II of barley seedlings under cadmium and lead stress. Plant Soil Environ 53(12):511

Malaspina P, Giordani P, Faimali M, Garaventa F, Modenesi P (2014) Assessing photosynthetic biomarkers in lichen transplants exposed under different light regimes. Ecol Ind 43:126-131

Mallick N, Mohn F (2003) Use of chlorophyll fluorescence in metalstress research: a case study with the green microalga Scenedesmus. Ecotoxicol Environ Saf 55(1):64-69

Mathur S, Mehta P, Jajoo A, Bharti S (2011a) Analysis of elevated temperature induced inhibition of Photosystem II using Chl a fluorescence induction kinetics. Plant Biology 13:1-6

Mathur S, Allakhverdiev SI, Jajoo A (2011b) Analysis of high temperature stress on the dynamics of antenna size and reducing side heterogeneity of Photosystem II in wheat leaves (Triticum aestivum). Biochim Biophys Acta 1807(1):22-29

Mathur S, Agrawal D, Jajoo A (2014) Photosynthesis: limitations in response to high temperature stress. J Photochem Photobiol B Biol. doi: 10.1016/j.jphotobiol.2014.01.010

Mehta P, Allakhverdiev SI, Jajoo A (2010a) Characterization of photosystem II heterogeneity in response to high salt stress in wheat leaves (Triticum aestivum). Photosynth Res 105(3):249-255

Mehta P, Jajoo A, Mathur S, Bharti S (2010b) Chlorophyll $a$ fluorescence study revealing effects of high salt stress on Photosystem II in wheat leaves. Plant Physiol Biochem 48(1):16-20

Melis A, Homann PH (1976) Heterogeneity of the photochemical centers in system II of chloroplasts. Photochem Photobiol 23:343-350

Mishra S, Dubey R (2005) Heavy metal toxicity induced alterations in photosynthetic metabolism in plants. In: Pessarakli M (ed) Handbook of photosynthesis, vol 28. CRC Press, Boca Raton, pp 827-844
Molassiotis A, Tanou G, Diamantidis G, Patakas A, Therios I (2006) Effects of 4-month Fe deficiency exposure on Fe reduction mechanism, photosynthetic gas exchange, chlorophyll fluorescence and antioxidant defense in two peach rootstocks differing in Fe deficiency tolerance. J Plant Physiol 163(2):176-185

Murata N, Mohanty P, Hayashi H, Papageorgiou G (1992) Glycinebetaine stabilizes the association of extrinsic proteins with the photosynthetic oxygen-evolving complex. FEBS Lett 296(2):187-189

Oukarroum A, Madidi SE, Schansker G, Strasser RJ (2007) Probing the responses of barley cultivars (Hordeum vulgare L.) by chlorophyll $a$ fluorescence OLKJIP under drought stress and rewatering. Environ Exp Bot 60(3):438-446

Oukarroum A, Schansker G, Strasser RJ (2009) Drought stress effects on photosystem I content and photosystem II thermotolerance analyzed using $\mathrm{Chl}$ a fluorescence kinetics in barley varieties differing in their drought tolerance. Physiol Plant 137(2):188-199

Oukarroum A, El Madidi S, Strasser RJ (2012) Exogenous glycine betaine and proline play a protective role in heat-stressed barley leaves (Hordeum vulgare L.): a chlorophyll a fluorescence study. Plant Biosyst 146(4):1037-1043

Papageorgiou GC, Govindjee (2011) Photosystem II fluorescence: slow changes - scaling from the past. J Photochem Photobiol B 104(1-2):258-270

Rampino P, Pataleo S, Gerardi C, Mita G, Perrotta C (2006) Drought stress response in wheat: physiological and molecular analysis of resistant and sensitive genotypes. Plant Cell Environ 29(12):2143-2152

Redillas MCFR, Jeong JS, Strasser RJ, Kim YS, Kim JK (2011) JIP analysis on rice (Oryza sativa cv Nipponbare) grown under limited nitrogen conditions. J Korean Soc Appl Biol Chem $54: 827-832$

Romanowska E, Igamberdiev AU, Parys E, Gardeström P (2002) Stimulation of respiration by $\mathrm{Pb}^{2+}$ in detached leaves and mitochondria of $\mathrm{C}_{3}$ and $\mathrm{C}_{4}$ plants. Physiol Plant 116(2):148-154

Romanowska E, Wróblewska B, Drożak A, Siedlecka M (2006) High light intensity protects photosynthetic apparatus of pea plants against exposure to lead. Plant Physiol Biochem 44(5):387-394

Schansker G, Srivastava A, Govindjee, Strasse RJ (2003) Characterization of the 820-nm transmission signal paralleling the chlorophyll $a$ fluorescence rise (OJIP) in pea leaves. Funct Plant Biol 30(7):785-796

Schreiber U, Neubauer C, Klughammer C (1989) Devices and methods for room-temperature fluorescence analysis. Philos Trans Royal Soc London B Biol Sci 323(1216):241-251

Schreiber U, Bilger W, Neubauer C (1994) Chlorophyll fluorescence as a nonintrusive indicator for rapid assessment of in vivo photosynthesis. Ecophysiology of photosynthesis. Springer, Berlin, pp 49-70

Schreiber U, Klughammer C, Kolbowski J (2012) Assessment of wavelength-dependent parameters of photosynthetic electron transport with a new type of multi-color PAM chlorophyll fluorometer. Photosynth Res 113(1-3):127-144

Schweiger J, Lang M, Lichtenthaler HK (1996) Differences in fluorescence excitation spectra of leaves between stressed and non-stressed plants. J Plant Physiol 148(5):536-547

Sharkey TD, Schrader SM (2006) High temperature stress. Physiology and molecular biology of stress tolerance in plants. Springer, Berlin, pp 101-129

Sharma P, Dubey RS (2005) Lead toxicity in plants. Brazilian Journal of Plant Physiology 17:35-52

Sigfridsson KG, Bernát G, Mamedov F, Styring S (2004) Molecular interference of $\mathrm{Cd}^{2+}$ with Photosystem II. Biochim Biophys Acta 1659(1):19-31 
Singh-Tomar R, Mathur S, Allakhverdiev SI, Jajoo A (2012) Changes in PSII heterogeneity in response to osmotic and ionic stress in wheat leaves (Triticum aestivum). J Bioenerg Biomembr 44:411-419

Smethurst CF, Garnett T, Shabala S (2005) Nutritional and chlorophyll fluorescence responses of lucerne (Medicago sativa) to waterlogging and subsequent recovery. Plant Soil 270(1):31-45

Srivastava A, Strasser RJ (1995) How do land plants respond to stress temperature and stress light? Arch Sci Geneve 48:135-146

Srivastava A, Strasser RJ, Govindjee (1999) Greening of peas: parallel measurements of $77 \mathrm{~K}$ emission spectra, OJIP chlorophyll $a$ fluorescence transient, period four oscillation of the initial fluorescence level, delayed light emission, and P700. Photosynthetica 37:365-392

Stefanov D, Petkova V, Denev ID (2011) Screening for heat tolerance in common bean (Phaseolus vulgaris L.) lines and cultivars using JIP-test. Sci Hortic 128(1):1-6

Stirbet A (2013) Excitonic connectivity between photosystem II units: what is it, and how to measure it? Photosynth Res 116:189-214

Stirbet A, Govindjee (2011) On the relation between the Kautsky effect (chlorophyll $a$ fluorescence induction) and Photosystem II: basics and applications of the OJIP fluorescence transient. J Photochem Photobiol B 104(1-2):236-257

Stirbet A, Govindjee (2012) Chlorophyll $a$ fluorescence induction: a personal perspective of the thermal phase, the J-I-P rise. Photosynth Res 113:15-61

Strasser RJ, Stirbet AD (1998) Heterogeneity of photosystem II probed by the numerically simulated chlorophyll $a$ fluorescence rise (O-J-I-P). Math Comput Simul 48(1):3-9

Strasser RJ, Srivastava A, Tsimilli-Michael M (2000) The fluorescence transient as a tool to characterize and screen photosynthetic samples. In: Mohanty P, Yunus, Pathre (eds) Probing photosynthesis: mechanism, regulation and adaptation. Taylor and Francis, London, pp 443-480

Strasser RJ, Tsimilli-Michael M, Srivastava A (2004) Analysis of the chlorophyll a fluorescence transient. In: Papageorgiou G, Govindjee (eds) Advances in photosynthesis and respiration. chlorophyll a fluorescence: a signature of photosynthesis. Springer, Dordrecht, pp 321-362

Strasser RJ, Tsimilli-Michael M, Srivastava A, Srivastava A (2005) Analysis of the chlorophyll $a$ fluorescence transient. In: Papageorgiou GC, Govindjee (eds) Advances in photosynthesis and respiration. Chlorophyll $a$ fluorescence: a signature of photosynthesis. Kluwer Acad. Publ, Dordrecht, pp 321-362

Strasser RJ, Tsimilli-Michael M, Qiang S, Goltsev V (2010) Simultaneous in vivo recording of prompt and delayed fluorescence and 820-nm reflection changes during drying and after rehydration of the resurrection plant Haberlea rhodopensis. Biochimical BiophysicalActa 1797:1313-1326

Strauss A, Krüger G, Strasser RJ, Heerden PV (2006) Ranking of dark chilling tolerance in soybean genotypes probed by the chlorophyll $a$ fluorescence transient OJIP. Environ Exp Bot 56(2):147-157

Streb P, Aubert S, Gout E, Feierabend J, Bligny R (2008) Cross tolerance to heavy-metal and cold-induced photoinhibiton in leaves of Pisum sativum acclimated to low temperature. Physiol Mole Biol Plants 14(3):185-193

Suzuki K, Ohmori Y, Ratel E (2011) High root temperature blocks both linear and cyclic electron transport in the dark during chilling of the leaves of rice seedlings. Plant Cell Physiology 52(9):1697-1707

Tomar RS, Jajoo A (2013) A quick investigation of the detrimental effects of environmental pollutant polycyclic aromatic hydrocarbon fluoranthene on the photosynthetic efficiency of wheat (Triticum aestivum). Ecotoxicology 22(8):1313-1318
Tomar RS, Jajoo A (2014) Fluoranthene, a polycyclic aromatic hydrocarbon, inhibits light as well as dark reactions of photosynthesis in wheat (Triticum aestivum). Ecotoxicol Environ Saf 109:110-115

Tsimilli-Michael M, Strasser RJ (2008) In vivo assessment of stress impact on plants' vitality: applications in detecting and evaluating the beneficial role of Mycorrhization on host plants. In: Varma A (ed) Mycorrhiza: state of the art, genetics and molecular biology, eco-function, biotechnology, eco-physiology, structure and systematics, vol 3rd. Springer, Berlin, pp 679-703

Tsimilli-Michael M, Strasser RJ (2013) The energy flux theory 35 years later: formulations and applications. Photosynth Res 117(1-3):289-320. doi:10.1007/s11120-013-9895-1

Tuba Z, Saxena DK, Srivastava K, Singh S, Czebol S, Kalaji MH (2010) Chlorophyll $a$ fluorescence measurements for validating the tolerant bryophytes for heavy metal $(\mathrm{Pb})$ biomapping. Curr Sci 98(11): 1505-1508

Van Heerden PD, Strasser RJ, Krüger GH (2004) Reduction of dark chilling stress in N2-fixing soybean by nitrate as indicated by chlorophyll $a$ fluorescence kinetics. Physiol Plant 121:239-249

Van Heerden PDR, Swanepoel JW, Krüger GHJ (2007) Modulation of photosynthesis by drought in two desert scrub species exhibiting $\mathrm{C}_{3}$-mode $\mathrm{CO}_{2}$ assimilation. Environ Exp Bot 61(2):124-136

Wu C, Wang Z, Sun H, Guo S (2006) Effects of different concentrations of nitrogen and phosphorus on chlorophyll biosynthesis, chlorophyll $a$ fluorescence, and photosynthesis in Larix olgensis seedlings. Front Forest China 1(2):170-175

Wu X, Hong F, Liu C, Su M, Zheng L, Gao F, Yang F (2008) Effects of $\mathrm{Pb}^{2+}$ on energy distribution and photochemical activity of spinach chloroplast. Spectrochimica Acta Part A Mol Biomol Spectrosc 69(3):738-742

Yamane Y, Kashino Y, Koike H, Satoh K (1997) Increases in the fluorescence Fo level and reversible inhibition of Photosystem II reaction center by high-temperature treatments in higher plants. Photosynth Res 52:57-64

Yang X, Liang Z, Wen X, Lu C (2008) Genetic engineering of the biosynthesis of glycinebetaine leads to increased tolerance of photosynthesis to salt stress in transgenic tobacco plants. Plant Mol Biol 66(1-2):73-86

Yang J, Kong Q, Xiang C (2009) Effects of low night temperature on pigments, chl a fluorescence and energy allocation in two bitter gourd (Momordica charantia L.) genotypes. Acta Physiologiae Plantarum 31(2):285-293

Zhang R, Sharkey TD (2009) Photosynthetic electron transport and proton flux under moderate heat stress. Photosynth Res 100(1):29-43

Zivcak M, Brestic M, Olsovska K, Slamka P (2008) Performance index as a sensitive indicator of water stress in Triticum aestivum. Plant Soil Environ 54:133-139

Zivcak M, Brestic M, Balatova Z, Drevenakova P, Olsovska K, Kalaji MH, Allakhverdiev SI (2013) Photosynthetic electron transport and specific photoprotective responses in wheat leaves under drought stress. Photosynth Res 117:529-546

Zivcak M, Kalaji MH, Shao HB, Olsovska K, Brestic M (2014). Photosynthetic proton and electron transport in wheat leaves under prolonged moderate drought stress. J Photochem Photobiol B Biol. doi: 10.1016/j.jphotobiol.2014.01.007

Zivcak M, Olsovska K, Slamka P, Galambosova J, Rataj V, Shao HB, Brestic M (2014b) Application of chlorophyll fluorescence performance indices to assess the wheat photosynthetic functions influenced by nitrogen deficiency. Plant Soil Environ 60:210-215

Zushi K, Kajiwara S, Matsuzoe N (2012) Chlorophyll $a$ fluorescence OJIP transient as a tool to characterize and evaluate response to heat and chilling stress in tomato leaf and fruit. Sci Hortic 148:39-46 